\title{
Divertor asymmetry and scrape-off layer flow in various divertor configurations in Experimental Advanced Superconducting Tokamak
}

Liu, S. C.; Guo, H. Y.; Xu, Guandong; Gao, X.; Zhu, S. Z.; Wang, H. Q.; Wang, L.; Yan, Ning; Wang, D. S.; Liu, $\mathbf{P}$.

Total number of authors:

20

Published in:

Physics of Plasmas

Link to article, DOI:

10.1063/1.4707396

Publication date:

2012

Document Version

Publisher's PDF, also known as Version of record

Link back to DTU Orbit

Citation (APA):

Liu, S. C., Guo, H. Y., Xu, G., Gao, X., Zhu, S. Z., Wang, H. Q., Wang, L., Yan, N., Wang, D. S., Liu, P., Jiang, M., Zhang, W., Ming, T. F., Chang, J. F., Ding, S. Y., Xiong, H., Shao, L. M., Wu, Z., Luo, G. N., \& EAST Team (2012). Divertor asymmetry and scrape-off layer flow in various divertor configurations in Experimental Advanced Superconducting Tokamak. Physics of Plasmas, 19(4), 042505. https://doi.org/10.1063/1.4707396

\section{General rights}

Copyright and moral rights for the publications made accessible in the public portal are retained by the authors and/or other copyright owners and it is a condition of accessing publications that users recognise and abide by the legal requirements associated with these rights.

- Users may download and print one copy of any publication from the public portal for the purpose of private study or research.

- You may not further distribute the material or use it for any profit-making activity or commercial gain

- You may freely distribute the URL identifying the publication in the public portal 


\section{AIP Plasmas}

\section{Divertor asymmetry and scrape-off layer flow in various divertor configurations in Experimental Advanced Superconducting Tokamak}

S. C. Liu, H. Y. Guo, G. S. Xu, X. Gao, S. Z. Zhu et al.

Citation: Phys. Plasmas 19, 042505 (2012); doi: 10.1063/1.4707396

View online: http://dx.doi.org/10.1063/1.4707396

View Table of Contents: http://pop.aip.org/resource/1/PHPAEN/v19/i4

Published by the American Institute of Physics.

\section{Related Articles}

Phase space structure of the electron diffusion region in reconnection with weak guide fields

Phys. Plasmas 19, 112108 (2012)

Optimized boundary driven flows for dynamos in a sphere

Phys. Plasmas 19, 112106 (2012)

Wave resonances and the partition of energy in ideal compressible magnetohydrodynamic fluids

Phys. Plasmas 19, 112104 (2012)

An electromagnetic theory of turbulence driven poloidal rotation

Phys. Plasmas 19, 102311 (2012)

Inclusion of diamagnetic drift effect in the matching method using finite-width inner region for stability analysis of magnetohydrodynamic modes

Phys. Plasmas 19, $102511(2012)$

\section{Additional information on Phys. Plasmas}

Journal Homepage: http://pop.aip.org/

Journal Information: http://pop.aip.org/about/about_the_journal

Top downloads: http://pop.aip.org/features/most_downloaded

Information for Authors: http://pop.aip.org/authors

\section{ADVERTISEMENT}

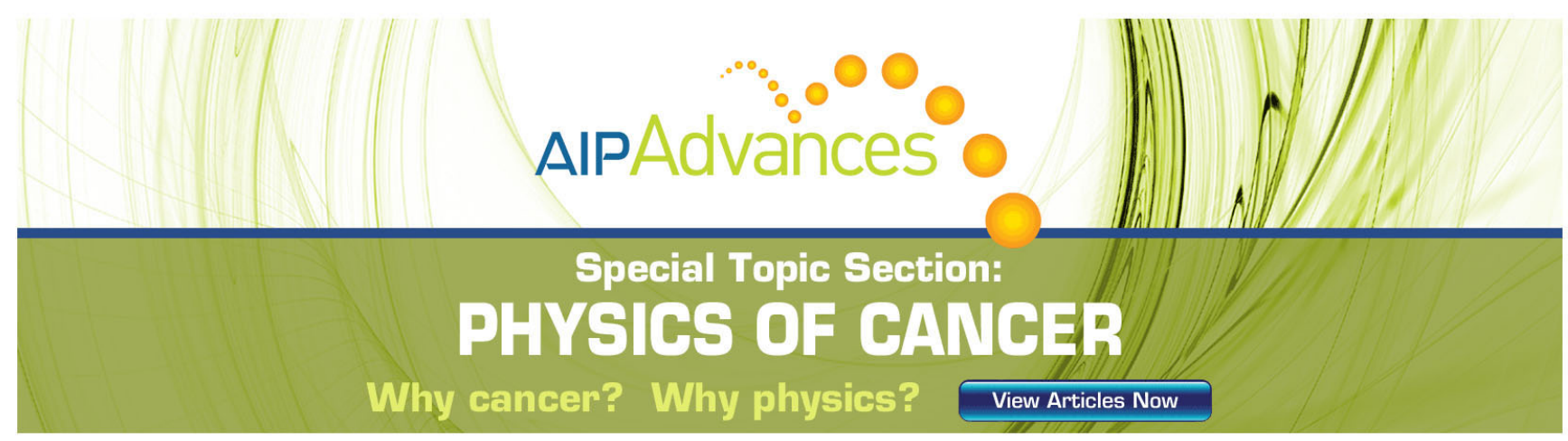




\title{
Divertor asymmetry and scrape-off layer flow in various divertor configurations in Experimental Advanced Superconducting Tokamak
}

\author{
S. C. Liu, ${ }^{1, a)}$ H. Y. Guo, ${ }^{1,2}$ G. S. Xu, ${ }^{1}$ X. Gao, ${ }^{1}$ S. Z. Zhu, ${ }^{1}$ H. Q. Wang, ${ }^{1}$ L. Wang, ${ }^{1}$ N. Yan,,${ }^{1,3}$ \\ D. S. Wang, ${ }^{1}$ P. Liu, ${ }^{1}$ M. Jiang, ${ }^{1}$ W. Zhang, ${ }^{1}$ T. F. Ming, ${ }^{1}$ J. F. Chang, ${ }^{1}$ S. Y. Ding, ${ }^{1}$ H. Xiong, ${ }^{1}$ \\ L. M. Shao, ${ }^{1}$ Z. W. Wu, ${ }^{1}$ G. N. Luo, ${ }^{1}$ and EAST Team ${ }^{1}$ \\ ${ }^{1}$ Institute of Plasma Physics, Chinese Academy of Science, Hefei 230031, China \\ ${ }^{2}$ Tri Alpha Energy, Inc., Post Office Box 7010, Rancho Santa Margarita, California 92688, USA \\ ${ }^{3}$ Association Euratom-Risф DTU, DK-4000 Roskilde, Denmark
}

(Received 9 November 2011; accepted 31 March 2012; published online 30 April 2012)

Divertor asymmetry and its dependence on the ion $\nabla \mathrm{B}$ direction has been investigated in the Experimental Advanced Superconducting Tokamak by changing the divertor configuration from lower single null (LSN), via double null (DN), to upper single null (USN) during one single discharge. Divertor plasmas exhibit the usual in-out asymmetry in particle and heat fluxes in LSN with the ion $\nabla \mathrm{B}$ direction toward the lower $\mathrm{X}$-point, favoring the outer divertor, especially at high density. The in-out asymmetry is reversed when changing the divertor configuration from LSN to USN, thus clearly demonstrating the effect of classical drifts. DN exhibits an even stronger in-out divertor asymmetry, favoring the outer divertor. A significant top-down asymmetry is also seen for DN, with greater particle and heat fluxes to the bottom divertor. In addition, the parallel plasma flow has been measured by a fast moving Mach probe at the outer midplane, which shows similar magnitude to the Pfirsch-Schlüter flow. Its contribution to the poloidal particle flux is also assessed and comparison is made with that from the poloidal $\mathbf{E} \times \mathbf{B}$ drift. (C) 2012 American Institute of Physics. [http://dx.doi.org/10.1063/1.4707396]

\section{INTRODUCTION}

Understanding of divertor asymmetry in particle and power fluxes to divertor targets is one of the most important issues for long pulse high power tokamak operation of the next step fusion devices, especially during H-mode operation, such as ITER. It has been found that for the lower single null (LSN) divertor configuration with normal magnetic field direction, i.e., the ion $\nabla \mathrm{B}$ drift toward the $\mathrm{X}$ point, the outer divertor plasma exhibits higher electron temperature $\mathrm{T}_{\mathrm{e}}$, lower electron density $\mathrm{n}_{\mathrm{e}}$, larger heat flux, and particle flux than the inner divertor plasma. In contrast, with reversed magnetic field, i.e., the ion $\nabla \mathrm{B}$ drift being directed away from $\mathrm{X}$ point, the divertor target parameter distribution is more symmetric between inner and outer divertors and, in some cases, even with a reversed divertor asymmetry. ${ }^{1-5}$ Several mechanisms are considered to influence divertor asymmetry, such as diamagnetic drift, $\mathbf{E} \times \mathbf{B}$ drift, Shafranov shift, divertor radiation, plasma rotation, as well as the effect of ballooning like transport and resulting asymmetry of inboard/outboard connection length. The asymmetry of connection length at inboard/outboard side also influences divertor asymmetry, especially for double null (DN) divertor operation. In LSN with normal magnetic field direction, it is considered that poloidal $\mathbf{E} \times \mathbf{B}$ drift, poloidal component of diamagnetic drift, and Shafranov shift enhance the outboard divertor asymmetry in heat flux, while the radial $\mathbf{E} \times \mathbf{B}$ drift component contributes to the inboard divertor asymmetry. ${ }^{6}$ In order to mitigate the in-out divertor asymmetry, some

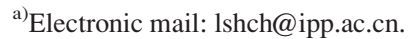

methods have been proposed, e.g., by reversing the toroidal magnetic field. ${ }^{7-9}$

The scrape-off layer (SOL) flow at various poloidal locations has been measured in many divertor tokamaks with both normal and reversed fields. ${ }^{10-14}$ Most of the experimental results are obtained by Mach probes. A number of possible mechanisms to drive the parallel SOL flow have been suggested, including ion Pfirsch-Schlüter (PS) flow, ballooning transport, flow reversal driven by localized ionization, momentum transfer, and co-current toroidal momentum generated in the SOL by ion $\nabla \mathrm{B}$ and centrifugal drifts. ${ }^{10}$ There are some experimental evidences that the PS flow appears to make an important contribution to the observed parallel flow, because the direction of the parallel flow is reversed when the magnetic field is reversed. ${ }^{10-13,15}$ In addition, It has been demonstrated by the measurements of the SOL flow in different divertor configurations at both high field side (HFS) and low field side (LFS) in Alcator C-Mod tokamak $^{12,13}$ that a ballooning-like transport is the most important contributing mechanism to the asymmetry in the HFS-LFS SOL flow, albeit some other mechanisms, including toroidal plasma rotation and PS ion currents, also contribute. ${ }^{5,12}$ Detailed analysis of poloidal particle flux has also been made to reveal dominating mechanisms for the SOL particle transport. ${ }^{11}$

Experimental Advanced Superconducting Tokamak (EAST) accommodates both single null and double null divertor configurations with a flexible poloidal field control system. Dedicated experiments have been carried out to investigate the divertor asymmetry by changing the divertor configuration from LSN, DN, to upper single null (USN) during a single discharge. This allows the clear comparison 
of the divertor asymmetry between the configurations with the ion $\nabla \mathrm{B}$ drift away and toward the active $\mathrm{X}$-point, thus demonstrating the effect of classical drifts. Furthermore, the plasma flow has been measured with the fast moving reciprocating probe at the outer midplane. Comparisons have been made between the measurements and predictions from the Pfirsch-Schlüter flow. Contributions of various drifts on the poloidal particle flux are also assessed.

\section{EXPERIMENTAL SETUP}

EAST is a fully superconducting tokamak with a major radius of $1.75 \mathrm{~m}$ and minor radius of $0.45 \mathrm{~m}$. EAST can operate in various divertor configurations, including USN, DN, and LSN divertor configurations. Fig. 1 shows a typical discharge with three different divertor configurations achieved during the same shot in EAST with $B_{t}=2 T, I_{p}=400 \mathrm{kA}$. Fig. 1(a) shows evolution of the ion saturation current densities at four divertor targets. Fig. 1(c) shows the evolution of $\mathrm{dR}_{\text {sep }}$ defined as the distance between the two $\mathrm{X}$ points mapped at LFS midplane, and $\mathrm{dR}_{\mathrm{sep}} \approx-2,0$, and $2 \mathrm{~cm}$ are in LSN, DN, and USN divertor topologies in our experiment, respectively.

Fig. 2 shows the poloidal locations of the divertor probes and reciprocating probes at the outer midplane of EAST. The divertor probes are configured as 74 triple probes
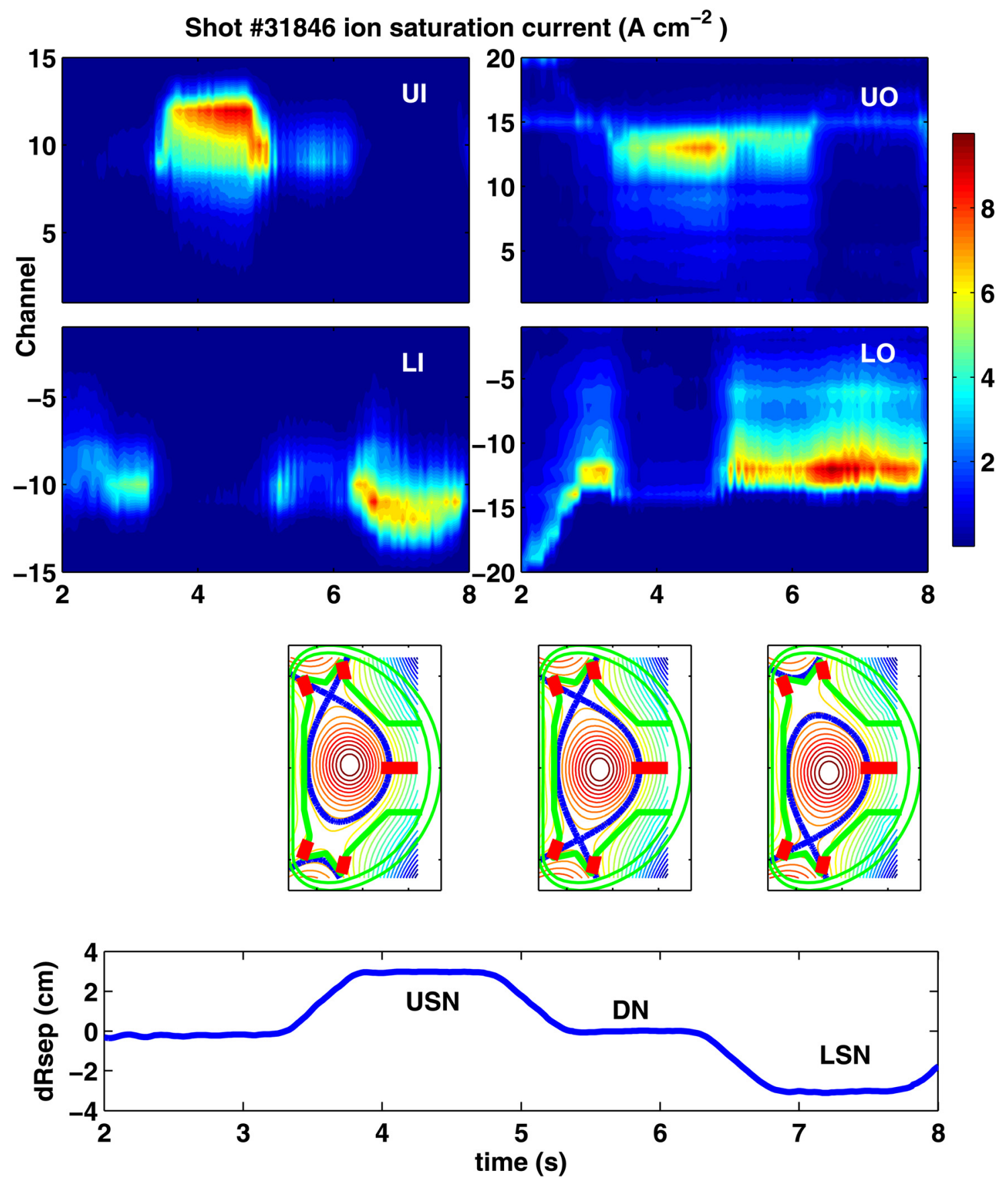

FIG. 1. Evolution of magnetic configuration for a typical discharge scanning through LSN, DN, and USN plasmas and quantified by distance of both separatrices $\left(\mathrm{dR}_{\mathrm{sep}}\right)$. 


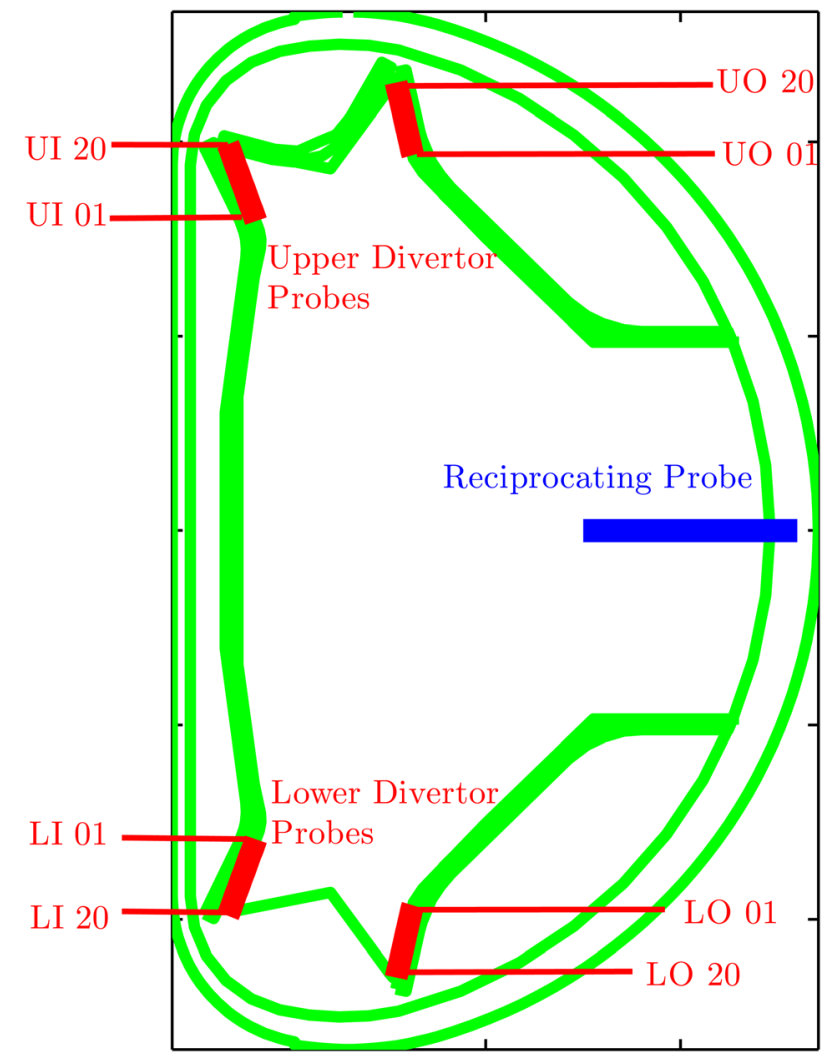

FIG. 2. Illustration of poloidal locations of divertor Langmuir probes (the red line at four divertor plates) and reciprocating probes (the blue line at LFS midplane) in EAST. UI-upper inboard divertor, UO-upper outboard divertor, $\mathrm{LI}$ - lower inboard divertor, and LO_lower outboard divertor.

which consist of 222 Langmuir probes embedded in the divertor target tiles to measure ion saturation current $\mathrm{j}_{\text {sat }}$, electron temperature $T_{e}$, and electron density $n_{e}$ at the four divertor targets with a spatial resolution of $15 \mathrm{~mm}$ and $10 \mathrm{~mm}$ at inner and outer divertor targets, respectively, with a time resolution of $0.2 \mathrm{~ms} .{ }^{16}$ The heat flux and particle flux are also calculated from the probe measurement. Two reciprocating probe systems have been installed through two horizontal ports at the LFS midplane of EAST with a toroidal displacement of $89^{\circ}$. The fast moving probe system has a maximum velocity of $2 \mathrm{~m} / \mathrm{s}$ and has the capability of making several strokes during a discharge of several seconds. ${ }^{17}$ Actual time resolution of the measurements is $0.2 \mu \mathrm{s}$. The probe head used in this particular experiment has 9 probe tips, including a triple probe and a Mach probe to measure the edge parameters like $\mathrm{n}_{\mathrm{e}}, \mathrm{T}_{\mathrm{e}}$, floating potential $\mathrm{V}_{\mathrm{f}}$, as well as Mach number of parallel flow in the LFS SOL.

\section{RESULTS AND DISCUSSION}

\section{A. Comparison of divertor asymmetry in LSN, DN, and USN at different densities}

The influence of central plasma density on divertor asymmetry is studied for the three divertor configurations, i.e., LSN, DN, and USN, during one discharge, especially LSN and USN. Figure 3 compares two discharges with different line averaged densities, $\overline{\mathrm{n}}_{\mathrm{e}}=0.5 \times 10^{19} \mathrm{~m}^{-3}$ and $0.9 \times 10^{19} \mathrm{~m}^{-3}$ for shot $\# 31729$ and 31737 , respectively, but other operating conditions remain the same, i.e., plasma current $\mathrm{I}_{\mathrm{p}}=400 \mathrm{kA}$, toroidal field $\mathrm{B}_{\mathrm{t}}=2 \mathrm{~T}, \mathrm{q}_{95} \sim 4$, and lower hybrid $(\mathrm{LH})$ wave heating power, $\mathrm{P}_{\mathrm{LHW}} \sim 0.2 \mathrm{MW}$. The particle and heat fluxes parallel to the field at the target surface are calculated from the divertor probe measurements as

$$
\begin{gathered}
\Gamma=\mathrm{n}_{\mathrm{i}} \mathrm{v}_{\mathrm{i}}=\mathrm{n}_{\mathrm{i}}\left(2 \mathrm{~T}_{\mathrm{i}} / \mathrm{m}_{\mathrm{i}}\right)^{1 / 2} \\
\mathrm{q}=\gamma \mathrm{kT}_{\mathrm{e}} \Gamma
\end{gathered}
$$

where $\gamma \approx 7$ is the total sheath heat transmission coefficient.

As can be seen, increasing the density from 0.5 to $0.9 \times 10^{19} \mathrm{~m}^{-3}$ leads to a significant change in the divertor plasma parameters at the target: electron temperature, $\mathrm{T}_{\mathrm{e}}$, reduces by nearly a half, and electron density, $\mathrm{n}_{\mathrm{e}}$, particle flux, $\Gamma$, and heat flux, $q$, increase 1.5-5 times. It should be noted that the heat flux increases significantly in the higher density case. This is presumably due to increased heating power, arising from enhanced Ohmic heating, as well as improved LH coupling at the higher density.

Divertor asymmetry exhibits a strong dependence on plasma density. Strong divertor asymmetry appears in the higher density case (shot \#31737) with much higher particle and heat fluxes at the outer target of the active divertor for the LSN divertor configuration, i.e., the lower divertor toward which the ion $\nabla \mathrm{B}$ drift is directed, as observed in other tokamaks, such as JT-60U, ${ }^{1,2} \mathrm{JET}^{3}$ Alcator C-Mod, ${ }^{18}$ and ASDEX-Upgrade. ${ }^{19}$ It was found in JT-60U that the heat flux even changes from inboard-enhanced to outboardenhanced with increasing density $\bar{n}_{e}$ in LSN with normal $B_{t}$, and an outboard-dominated heat flux changes to a symmetric one with reversed $\mathrm{B}_{\mathrm{t}}{ }^{1}$ In contrast, the in-out divertor asymmetry is clearly reduced at the lower density (shot \#31729). This is consistent with the prediction from the 2D fluid code, SOLPS, for similar plasma conditions in EAST ${ }^{20}$ Note that the line averaged densities of these two shots are relatively low; the ion saturation current measurements indicate that the divertor plasma is in the attached regime for both cases. Nevertheless, higher radiation in the divertor region is expected for the higher density discharge (\#31737), as evidenced by the larger $\mathrm{D}_{\alpha}$ emission than the lower density case (\#31729). In addition, the $\mathrm{D}_{\alpha}$ emission in the inner divertor is larger than that in the outer divertor, which may lead to the enhanced heat flux at the outboard divertor target. However, detailed local radiation measurements are currently unavailable due to a lack of bolometry, which will be implemented in the near future.

Figure 4 shows the target profiles at the upper divertor in USN with the ion $\nabla \mathrm{B}$ drift direction away from the divertor. This effectively mimics the usual $\mathrm{SN}$ divertor situation with reversed $B_{t}$. It is remarkable that the in-out asymmetry is reversed at the higher density (shot \#31737), i.e., with greater particle and heat fluxes at the inner divertor target, in contrast to LSN. This in-out divertor asymmetry remains similar at the lower density (shot \#31729), albeit with lower particle and heat fluxes at both inboard and outboard divertor targets. The asymmetry of $\mathrm{D}_{\alpha}$ emission also reverses and turns to outboard-enhanced. 


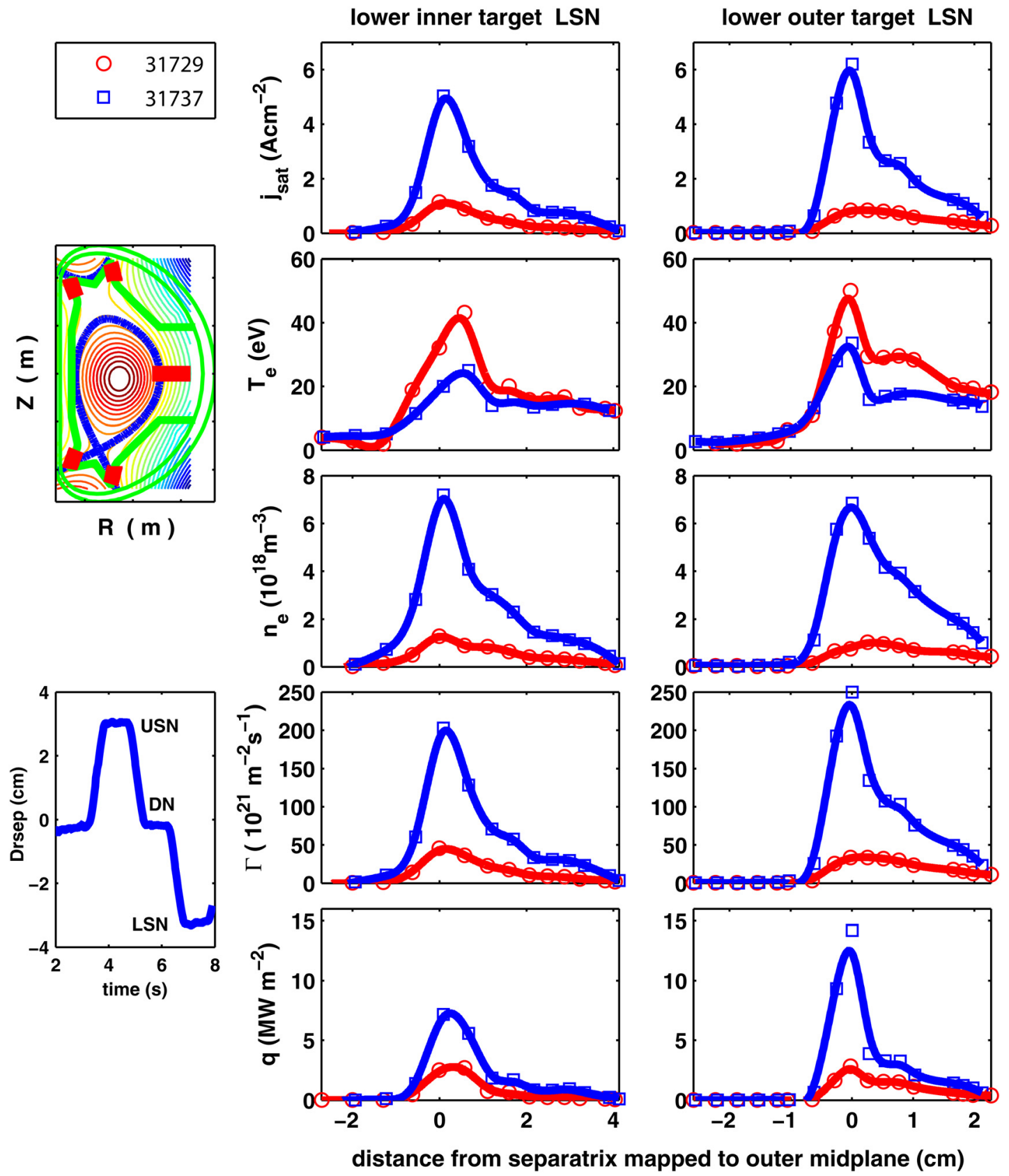

FIG. 3. In-out asymmetry of divertor targets in the LSN topology. Distance from the separatrix is mapped to the LFS midplane. Circle (red) and square (blue) are shot \#31729 and \#31737, with line average density $\bar{n}_{e}=0.5 \times 10^{19} \mathrm{~m}^{-3}$ and $0.9 \times 10^{19} \mathrm{~m}^{-3}$, respectively. Toroidal field $\mathrm{B}_{\mathrm{t}}$ is $2 \mathrm{~T}$, normal direction. Plasma current $I_{p}$ is $400 \mathrm{kA}$. The left side is inner target, and the right side is outer target. The target parameters shown here are ion saturate current $\mathrm{j}_{\mathrm{sat}}$, electron temperature $T_{e}$, electron density $n_{e}$, particle flux $\Gamma$, and heat flux q.

Comparison between LSN and USN clearly shows a strong correlation between the in-out divertor asymmetry and the ion $\nabla \mathrm{B}$ drift direction. This, at least in part, arises from the classical drifts. In contrast to diamagnetic drifts $\mathrm{v}_{\nabla \mathrm{p}}=\mathbf{B} \times \nabla \mathrm{p} / \mathrm{enB}^{2}$ which are largely divergence free and do not constitute fluxes onto external surface like target surface, $\mathbf{E} \times \mathbf{B}$ drift plays an important role in divertor asymmetry. For LSN with normal $\mathrm{B}_{\mathrm{t}}$, poloidal $\mathbf{E}_{\mathbf{r}} \times \mathbf{B}$ drift drives a plasma flow from the inner divertor to outer divertor along the field lines, while radial $\mathbf{E}_{\theta} \times \mathbf{B}$ drift drives a flow across the last closed flux surface (LCFS) from the outer SOL into the main plasma and out again across the LCFS into the inner SOL. ${ }^{21}$ Furthermore, $\mathbf{E}_{\mathbf{r}} \times \mathbf{B}$ drift via the private region from the outer divertor to inner divertor may also be important due to strong radial temperature gradients present in the private region. For USN, all the aforementioned drifts are reversed similar to the $\mathrm{LSN}$ case with reversed $\mathrm{B}_{\mathrm{t}}$, thus exhibiting the same trend as the reversal of divertor asymmetry. The radiation also influences the in-out divertor asymmetry via reducing $T_{e}$ at divertor targets, i.e., inboard-enhanced divertor radiation for LSN and outboard-enhanced divertor radiation for USN, leading to outboard-enhanced target heat flux for LSN and inboard-enhanced target heat flux for USN, respectively. However, the in-out asymmetry is very complex and has not yet been quantitatively reproduced with modeling up to date. ${ }^{3}$ 


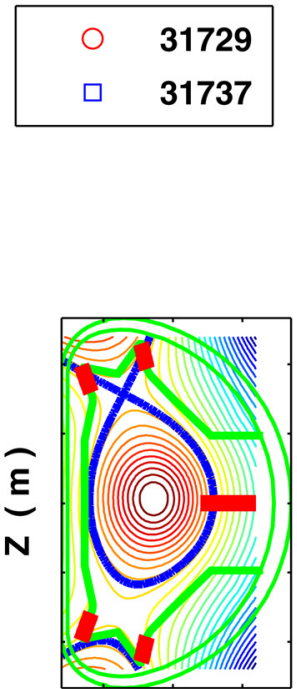

$R(m)$
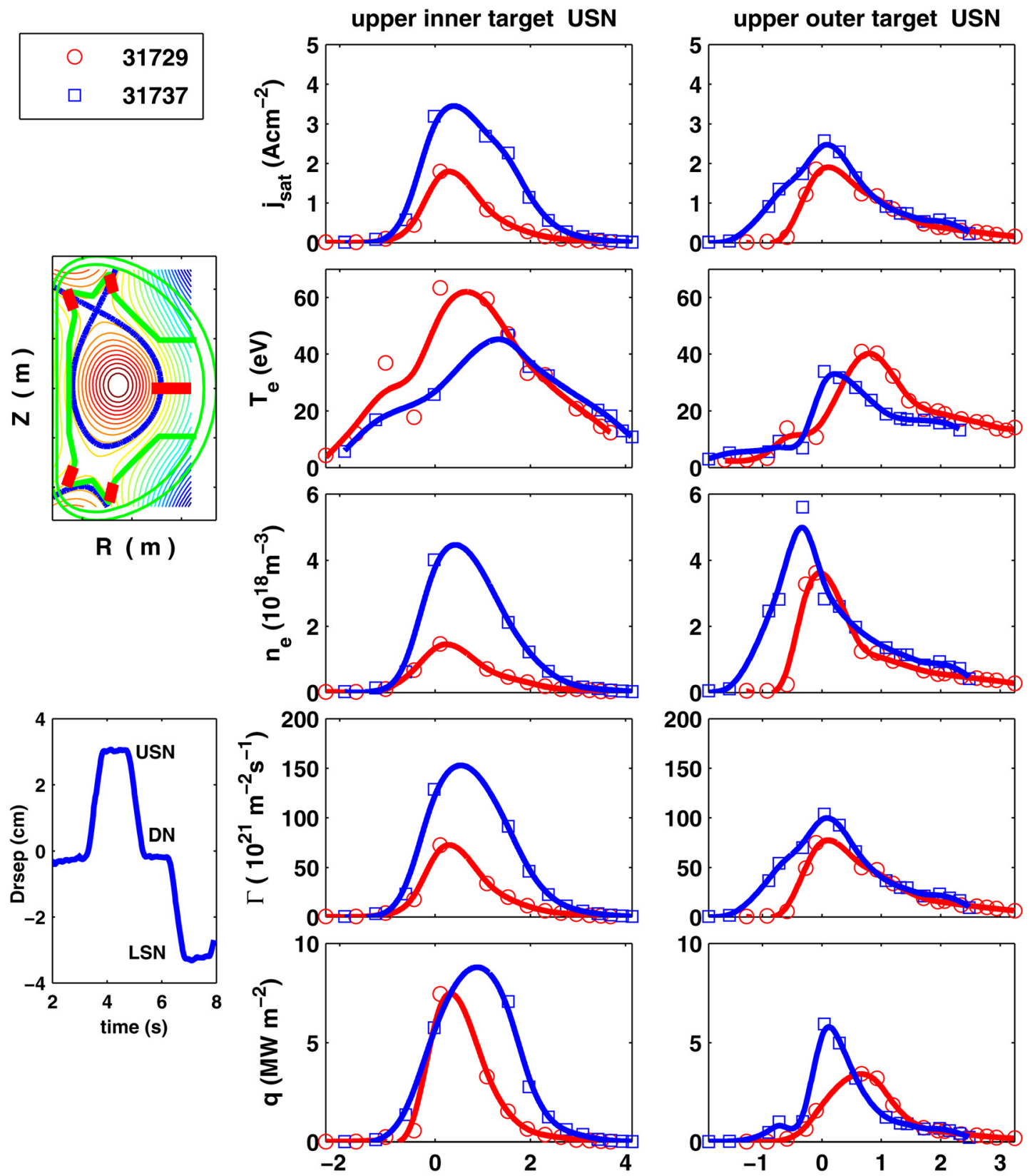

distance from separatrix mapped to outer midplane $(\mathrm{cm})$

FIG. 4. Same as Fig. 3 for USN topology. The asymmetry of particle flux and heat flux reverses, changing from an outboard-enhanced asymmetry for LSN to an inboard-enhanced asymmetry for USN.

For DN, the divertor also exhibits an in-out asymmetry with large particle and heat fluxes to the outer target, as shown in Fig. 5, similar to that for LSN, albeit less pronounced. Note that, for DN and near DN divertor configurations, the in-out divertor asymmetry is also affected by the divertor magnetic balance, ${ }^{22}$ as characterized by the distance between primary and secondary separatrices, $d R_{\text {sep }}=R_{\mathrm{L}}$ $-R_{\mathrm{U}}$, where $R_{\mathrm{L}}$ and $R_{\mathrm{U}}$ are the lower and upper separatrix radii mapped to the outer midplane; $d R_{\text {sep }}=0$ for a wellbalanced DN divertor configuration. It is anticipated that divertor targets receive less power for DN than SN. Contrary to the expectation, the peak heat flux for DN also appears to be comparable to that for LSN, despite presumably doubled plasma wetted area, including both upper and lower divertor targets. The temporal evolution of $d R_{\text {sep }}$ and ratio of power at the inner target to those at the outer target are shown in Fig. 6, where the ratio is expressed as $\mathrm{P}_{\mathrm{HFS}} / \mathrm{P}_{\mathrm{LFS}}$, with the divertor configuration changing from USN, via DN, to LSN. As can be seen, $\mathrm{P}_{\mathrm{HFS}} / \mathrm{P}_{\mathrm{LFS}}$ reaches its minimum for $\mathrm{DN}$. Clearly, the outer divertor receives significantly greater power than the inner divertor, presumably due to a large power flow across separatrix into the outer divertor, arising from, e.g., a large surface area and enhanced radial power transport on the outboard side, as mentioned in Sec. I.

It should be noted that much more particle and heat fluxes go to the lower divertor. Such an up-down asymmetry 


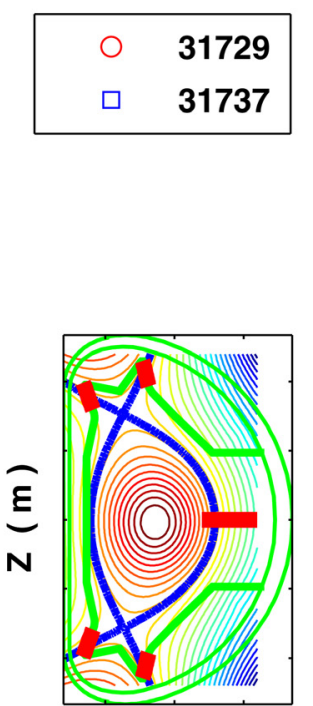

R ( m )
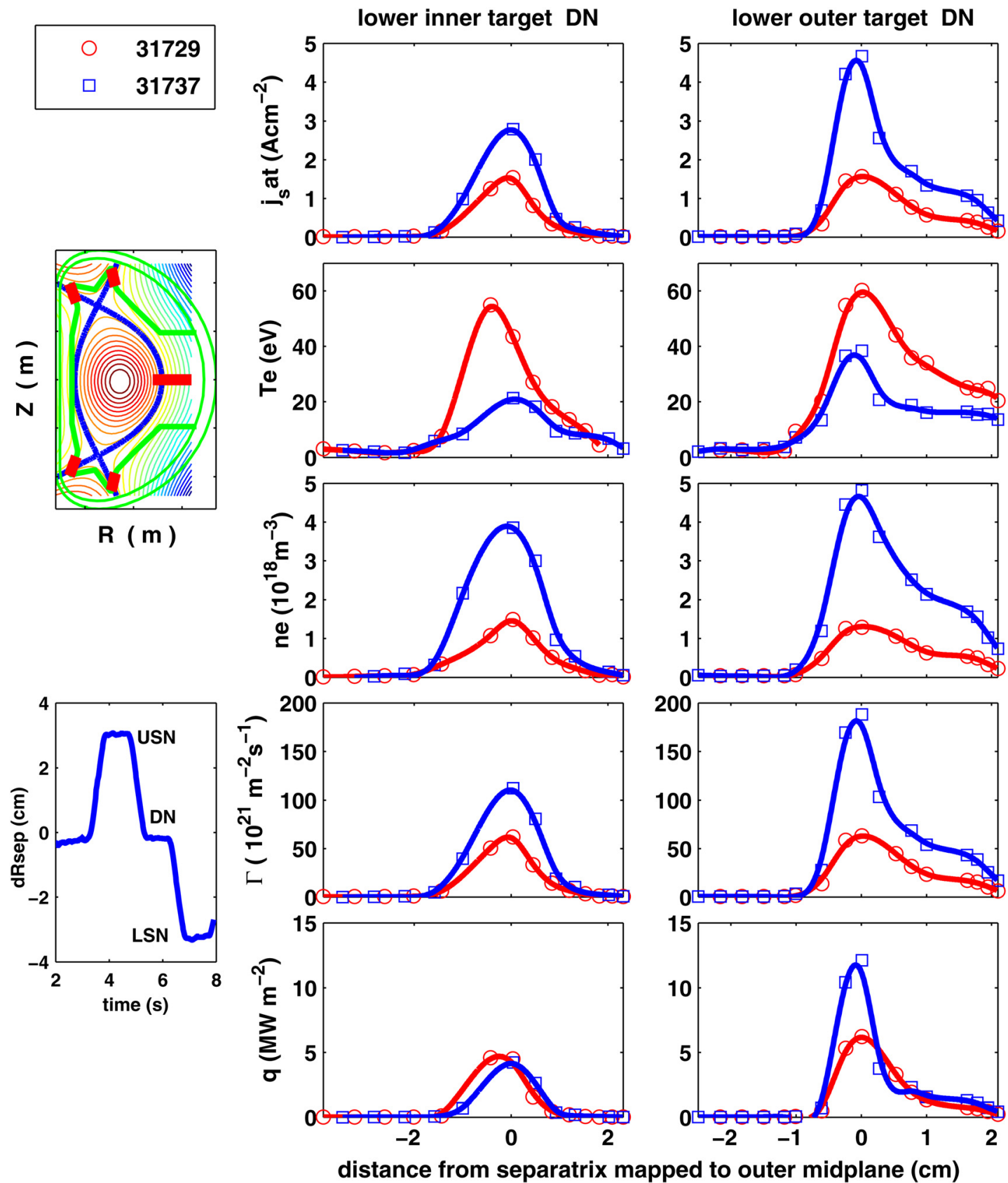

FIG. 5. Same as Fig. 3 for lower targets in DN topology.

has been shown to correlate with the ion $\nabla \mathrm{B}$ drift direction, i.e., with higher particle flux, heat flux, and pressure in the active divertor of the $\mathrm{DN}$ configuration. ${ }^{23,24}$

\section{B. Parallel SOL flow}

In order to investigate the SOL flow in EAST, a series of ohmic discharges were performed in LSN, DN, and USN divertor configurations with $\mathrm{I}_{\mathrm{p}}=400 \mathrm{kA}, \mathrm{B}_{\mathrm{t}}=2 \mathrm{~T}$, in normal field direction. Figure 7 shows the profiles of floating potential $V_{f}, T_{e}, n_{e}$, electron pressure $p_{e}$, as well as parallel Mach number for the three configurations, i.e., LSN, USN, and $\mathrm{DN}$. The Mach number is calculated as

$$
\mathrm{M}=0.4 \ln \left(\mathrm{j}_{1} / \mathrm{j}_{2}\right)
$$

where $j_{1}$ and $j_{2}$ are the saturated ion current densities on each side of a Mach probe.

It appears that there are no significant differences in the midplane profiles for the different divertor configurations. Mach numbers are in the range of $-0.1 \sim 0.3$ for the three topologies. Since $\mathrm{B}_{\mathrm{t}}$ is in the normal field direction (clockwise, viewing from above the machine) and $I_{p}$ is in reversal direction (counter-clockwise), a positive Mach number means that parallel flow is in the same direction as the plasma current, i.e., toward the top of the machine, at outer midplane, while a negative Mach number indicates the plasma flow toward plasma bottom. When approaching the separatrix, Mach number first increases, then rolls over, and starts to decrease, even to a negative value inside the separatrix. It should be noted that the direction of the parallel flow 

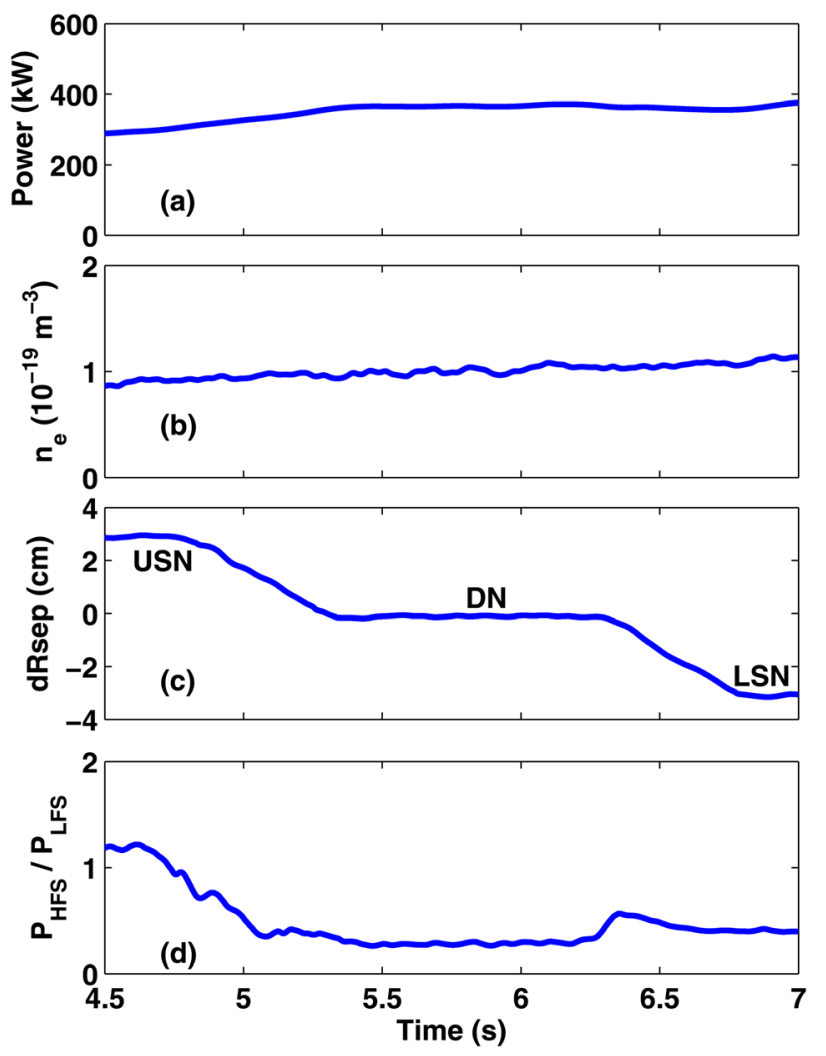

FIG. 6. (a) Total heating power; (b) line averaged density; (c) evolution of $\mathrm{dR}_{\text {sep }}$, i.e., the distance between primary and secondary separatrices; and (d) evolution of the ratio of power at inner divertor target to the outer divertor target. $\mathrm{P}_{\mathrm{HFS}}$ is the total power at upper inner and lower inner targets, and $\mathrm{P}_{\mathrm{LFS}}$ is the sum of power at upper outer and lower outer target. The ratio of $\mathrm{P}_{\mathrm{HFS}} / \mathrm{P}_{\mathrm{LFS}}$ reaches a minimum with the DN topology.

is independent of the divertor configurations. However, the Mach number appears to be smaller in LSN than the other divertor configurations in the far SOL, away from the separatrix.

As mentioned in Sec. I, the parallel flow may be driven by the poloidal asymmetry of the classical drifts, i.e., the PS flow and turbulences originated from the outboard SOL due to bad field line curvatures. Since the probe is located at the outer midplane of EAST, the effective contribution from the turbulence driven transport to the parallel flow should be small. The PS flow is driven by the poloidal asymmetry of the classical drifts and is given by Ref. 25, with the direction upwards in SOL for normal field. PS flow is calculated by formula below

$$
\mathrm{V}_{\mathrm{ps}}=2 \mathrm{q} \cos \theta\left(\mathrm{E}_{\mathrm{r}}-\frac{\nabla_{\mathrm{r}} \mathrm{p}_{\mathrm{i}}}{\mathrm{en}}\right) \times \frac{\mathbf{B}_{0}}{\mathrm{~B}^{2}},
$$

where $\mathrm{q}=\mathrm{rB}_{0} / \mathrm{R}_{0} \mathrm{~B}_{\theta}$ is the safety factor, $\theta=0$ at the outer midplane, and $E_{r}=-d\left(V_{\mathrm{f}}+2.8 \mathrm{~T}_{\mathrm{e}}\right) / \mathrm{dr}$, assuming $\mathrm{p}_{\mathrm{i}}=\mathrm{p}_{\mathrm{e}}{ }^{15}$ The PS flow is maximum and directed upwards in the midplane SOL for normal field.

As an example, Fig. 8(a) compares the measured parallel flow with the PS flow for USN. As can be seen, the calculated PS flow is largely consistent with the measured parallel flow in the far SOL, in agreement with the results from other tokamaks. ${ }^{10,12,15}$ Near the separatrix, other mechanisms play

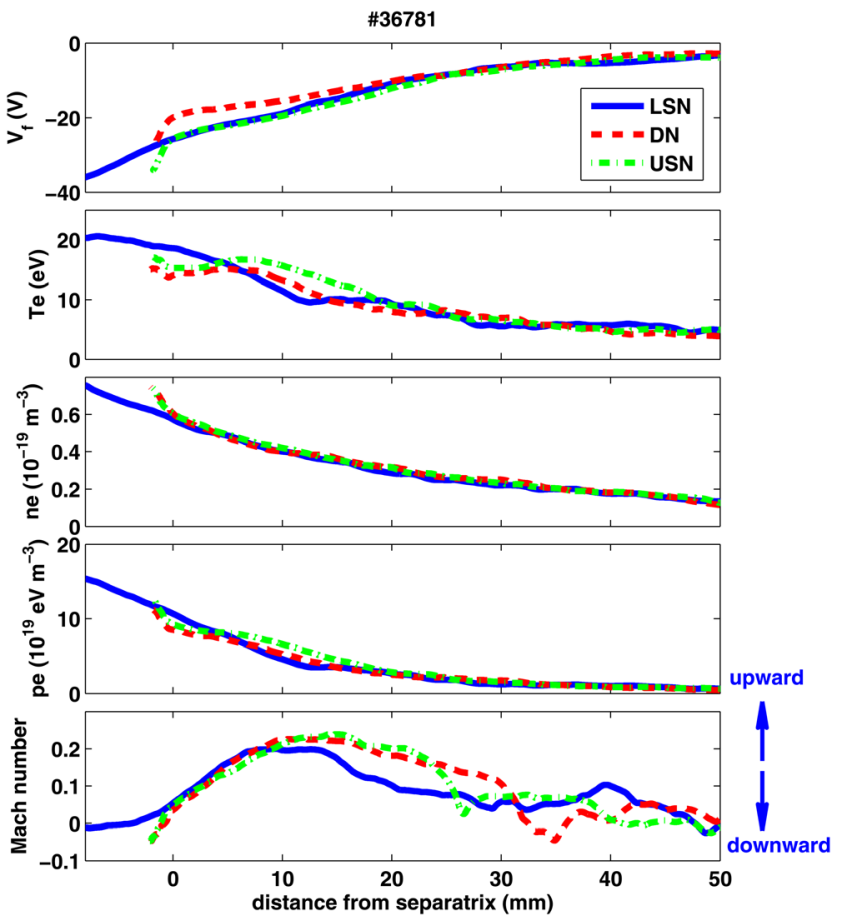

FIG. 7. Parameters measured by reciprocating probes at outer midplane in three magnetic topologies, including floating potential, $\mathrm{T}_{\mathrm{e}}, \mathrm{n}_{\mathrm{e}}$, electron pressure $\mathrm{p}_{\mathrm{e}}$, and parallel Mach number from top to down. The positive and negative Mach numbers represent the directions toward the top and bottom of plasma at outer midplane, respectively.

an important role in driving the parallel flow, such as toroidal rotation and cross-field transport.

Figure 8(b) compares the contribution from the parallel flow to the poloidal particle flux with that from the poloidal $\mathbf{E} \times \mathbf{B}$ drift. The total poloidal particle flux in SOL is calculated by integrating the parallel flow component $\left(\mathrm{V}_{\|} \Theta\right)$ and poloidal $\mathbf{E} \times \mathbf{B}$ drift $\left(\mathrm{V}_{\mathbf{E x B}} \phi\right)$ across the SOL from separatrix (0) to the outermost radius $\left(\lambda_{\mathrm{SOL}}\right)^{11}$

$$
\Gamma_{\mathrm{p}}=\int_{0}^{\lambda_{\mathrm{SOL}}} 2 \pi \mathrm{R}\left(\mathrm{n}_{\mathrm{i}} \mathrm{V}_{\|} \Theta+\mathrm{n}_{\mathrm{i}} \mathrm{V}_{\mathbf{E} \times \mathbf{B}} \phi\right) \mathrm{dr},
$$

where $\Theta=\mathrm{B}_{\mathrm{p}} / \mathrm{B}_{\|} \approx \mathrm{B}_{\mathrm{p}} / \mathrm{B}_{0}, \quad \phi=\mathrm{B}_{\mathrm{t}} / \mathrm{B}_{\|} \approx 1$. Obviously, the poloidal flow component of the parallel flow is directed toward the top of the machine, while the poloidal $\mathbf{E} \times \mathbf{B} \mathrm{drift}$ component is toward the bottom. However, the overall poloidal particle flux is dominated by the contribution from the poloidal $\mathbf{E} \times \mathbf{B}$ drift, directing toward the bottom in most SOL region. If considering the contribution of the diamagnetic drift $\mathrm{B}_{\mathrm{t}} \times \nabla \mathrm{p}$ that has the same magnitude and direction as the poloidal $\mathbf{E} \times \mathbf{B}$ drift in outer SOL, the particle flux toward the bottom will be enhanced.

\section{SUMMARY AND CONCLUSIONS}

A series of dedicated experiments have been performed to investigate the divertor asymmetry and plasma flow in the boundary layer using a large array of triple Langmuir probes embedded in the divertor target plates and a fast moving Mach probe located at the outer midplane. Both in-out and top-down divertor asymmetries in particle and heat fluxes 


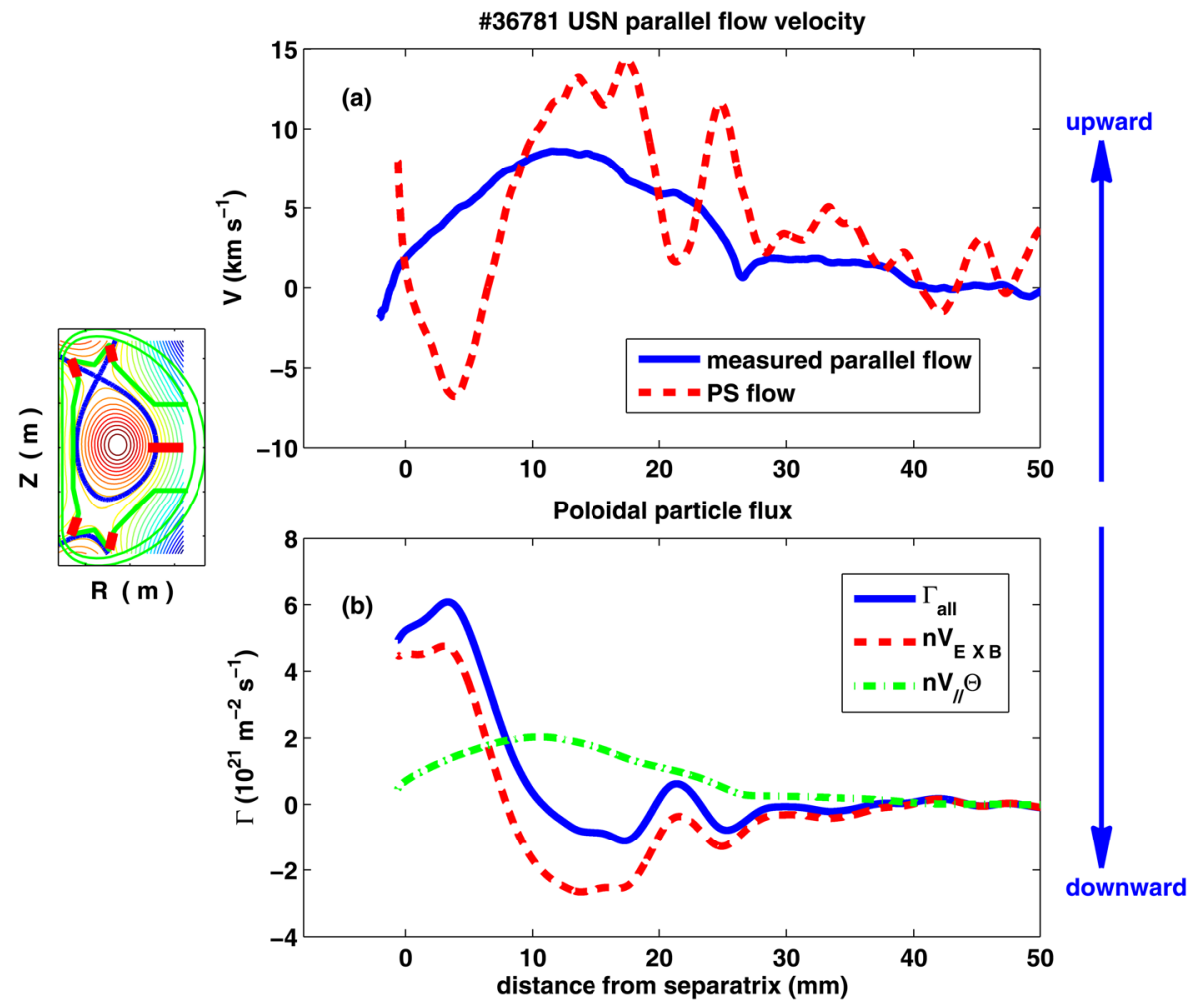

FIG. 8. Parallel flow velocity (a) and poloidal particle flux (b) in USN configuration. Positive and negative values represent the direction toward plasma top and bottom, respectively.

have been determined by varying the divertor configuration from LSN, via DN, to USN during one single discharge. Divertor asymmetry is strongly dependent on plasma conditions and magnetic configurations. It was found that LSN, with the ion $\nabla \mathrm{B}$ drift directed toward the lower $\mathrm{X}$-point, exhibits a strong asymmetry with higher particle and heat fluxes to the outer divertor target at a higher density, i.e., $\mathrm{n}_{\mathrm{e}}=0.9 \times 10^{19} \mathrm{~m}^{-3}$, compared to the lower density case, i.e., $\mathrm{n}_{\mathrm{e}}=0.5 \times 10^{19} \mathrm{~m}^{-3}$. The in-out divertor asymmetry is reversed for USN where the ion $\nabla \mathrm{B}$ drift is directed away from the upper X-point, thus clearly demonstrating the effect of classical drifts. Radiation also leads to these divertor heat flux asymmetries for LSN and USN. The DN operation leads to an even stronger in-out divertor asymmetry, favoring the outer divertor. In addition, DN exhibits a significant topdown asymmetry, with higher particle and heat fluxes to the bottom divertor in the ion $\nabla \mathrm{B}$ drift direction. Detailed modeling using the solPs code will be carried out to further assess the role of classical drifts.

SOL parallel flow was also measured in LSN, DN, and USN. The radial profile of Mach number shows similar characteristics in the three divertor configurations: Mach number increases in SOL when approaching LCFS, then rolls over, and finally reduces rapidly in the vicinity of separatrix, even to a negative value, with Mach number between -0.1 and 0.3 , which is roughly consistent with the calculated PS flow. In addition, the measured parallel flow is toward the top of the machine, independent of the divertor configurations, in the same direction as the PS flow. This suggests that the parallel flow may be dominated by the PS flow. To further verify this, experiments with field reversal will be carried in the next EAST experimental campaign. Detailed analysis shows that the poloidal particle flux due to the poloidal component of parallel flow is small compared with that produced by poloidal $\mathbf{E} \times \mathbf{B}$ drift toward the bottom divertor, especially near the separatrix. This, along with the diamagnetic drift $\mathrm{B}_{\mathrm{t}} \times \nabla \mathrm{p}$, which is in the same direction as the poloidal $\mathbf{E} \times \mathbf{B}$ drift, would further enhance the poloidal flow toward the bottom divertor.

More work is needed to study the power loading in divertor, particle, and power transport in SOL during $\mathrm{H}$-mode in EAST. Simulations should be introduced into our research to analyze the experiment results, e.g., using solPs and heuristic drift-based model ${ }^{26,27}$ to study the SOL flow and divertor performance.

\section{ACKNOWLEDGMENTS}

We would like to thank the EAST Team for their cooperation and kind help. This work is supported by the National Magnetic Confinement Fusion Research Program of China under Contract Nos. 2010GB104001, 2010GB106000, and 2010GB106001, and the National Natural Science Foundation of China under Grant No. 11105177.

${ }^{1}$ N. Asakura, K. Itami, N. Hosogane, S. Tsuji, K. Shimizu, H. Kubo, T. Sugie, T. Takizuka, and M. Shimada, J. Nucl. Mater. 220-222, 395 (1995).

${ }^{2}$ N. Asakura, H. Hosogane, S. Tsuji-iio, K. Itami, K. Shimizu, and M. Shimada, Nucl. Fusion 36, 795 (1996).

${ }^{3}$ A. V. Chankin, D. J. Campbell, S. Clement, S. J. Davies, L. D. Horton, J. Lingertat, A. Loarte, G. F. Matthews, R. D. Monk, R. Reichle, G. Saibene, M. Stamp, and P. C. Stangeby, Plasma Phys. Controlled Fusion 38, 1579 (1996).

${ }^{4}$ T. Eich, A. Kallenbach, R. A. Pitts, S. Jachmich, J. C. Fuchs, A. Herrmann, J. Neuhauser, ASDEX Upgrade Team, and JET-EFDA Contributors, J. Nucl. Mater, 363-365, 989 (2007).

${ }^{5}$ T. Eich, A. Herrmann, J. Neuhauser, R. Dux, J. C. Fuchs, S. Günter, L. D. Horton, A. Kallenbach, P. T. Lang, C. F. Maggi, M. Maraschek, V. Rohde, 
W. Schneider, and the ASDEX Upgrade Team, Plasma Phys. Controlled Fusion 47, 815 (2005).

${ }^{6}$ P. C. Stangeby and A. V. Chankin, Nucl. Fusion 36, 839 (1996).

${ }^{7}$ U. Wenzel, D. P. Coster, A. Kallenbach, H. Kastelewicz, M. Laux, H. Maier, R. Schneider, and ASDEX Upgrade Team, Nucl. Fusion 41, 1695 (2001).

${ }^{8}$ P. Andrew, J. P. Coad, Y. Corre, T. Eich, A. Herrmann, G. F. Matthews, J. I. Paley, L. Pickworth, R. A. Pitts, M. F. Stamp, and JET EFDA Contributors, J. Nucl. Mater. 337-339, 99 (2005).

${ }^{9}$ A. Huber, J. Rapp, P. Andrew, P. Coad, G. Corrigan, K. Erents, W. Fundamenski, L. C. Ingesson, S. Jachmich, A. Korotkov, G. F. Matthews, Ph. Mertens, V. Philipps, R. Pitts, B. Schweer, G. Sergienko, M. Stamp, and JET EFDA Contributors, J. Nucl. Mater. 337-339, 241 (2005).

${ }^{10}$ S. K. Erents, A. V. Chankin, G. F. Matthews, and P. C. Stangeby, Plasma Phys. Controlled Fusion 42, 905 (2000).

${ }^{11}$ N. Asakura, H. Takenaga, S. Sakurai, G. D. Porter, T. D. Rognlien, M. E. Rensink, K. Shimizu, S. Higashijima, and H. Kubo, Nucl. Fusion 44, 503 (2004).

${ }^{12}$ B. LaBombard, J. E. Rice, A. E. Hubbard, J. W. Hughes, M. Greenwald, J. Irby, Y. Lin, B. Lipschultz, E. S. Marmar, C. S. Pitcher, N. Smick, S. M. Wolfe, S. J. Wukitch, and the Alcator Group, Nucl. Fusion 44, 1047 (2004).

${ }^{13} \mathrm{~N}$. Asakura, ITPA SOL, and Divertor Topical Group, J. Nucl. Mater. 363-365, 41 (2007).

${ }^{14}$ M. Tsalas, A. Herrmann, A. Kallenbach, H. W. Müller, J. Neuhauser, V. Rohde, N. Tsois, M. Wischmeier, and the ASDEX Upgrade Team, Plasma Phys. Controlled Fusion 49, 857 (2007).

${ }^{15}$ N. Asakura, S. Sakurai, M. Shimada, Y. Koide, N. Hosogane, and K. Itami, Phys. Rev. Lett. 84, 3093 (2000).
${ }^{16}$ T. F. Ming, W. Zhang, J. F. Chang, J. Wang, G. S. Xu, S. Y. Ding, N. Yan, X. Gao, and H. Y. Guo, Fusion Eng. Des. 84, 57 (2009).

${ }^{17}$ W. Zhang, J. F. Chang, B. N. Wan, G. S. Xu, C. J. Xiao, B. Li, C. S. Xu, N. Yan, L. Wang, S. C. Liu, M. Jiang, and P. Liu, Rev. Sci. Instrum. 81, 113501 (2010).

${ }^{18}$ I. H. Hutchinson, B. LaBombard, J. A. Goetz, B. Lipschultz, G. M. McCracken, J. A. Snipes, and J. L. Terry, Plasma Phys. Controlled Fusion 37, 1389 (1995).

${ }^{19}$ N. Tsois, C. Dorn, G. Kyriakakis, M. Markoulaki, M. Pflug, G. Schramm, P. Theodoropoulos, P. Xantopoulos, M. Weinlich, and the ASDEX Upgrade Team, J. Nucl. Mater. 266-269, 1230 (1999).

${ }^{20}$ H. Y. Guo, S. Zhu, and J. Li, J. Nucl. Mater. 363-365, 162 (2007).

${ }^{21}$ P. C. Stangeby, The Plasma Boundary of Magnetic Fusion Devices (Institute of Physics Publishing, Bristol, 2000), p. 268.

${ }^{22}$ H. Y. Guo, X. Gao, J. Li, G. N. Luo, S. Zhu, J. F. Chang, Y. P. Chen, W. Gao, X. Z. Gong, Q. S. Hu, Q. Li, S. C. Liu, T. F. Ming, J. Ou, Y. J. Shi, B. N. Wan, D. S. Wang, H. Q. Wang, J. Wang, Z. W. Wu, B. J. Xiao, Q. Xu, L. Zhang, and W. Zhang, J. Nucl. Mater. 415, S369 (2011).

${ }^{23}$ A. V. Chankin and P. C. Stangeby, Nucl. Fusion 41, 421 (2001).

${ }^{24}$ A. V. Chankin, G. Corrigan, S. K. Erents, G. F. Matthews, J. Spence, and P. C. Stangeby, J. Nucl. Mater. 290-293, 518 (2001).

${ }^{25}$ P. C. Stangeby, The Plasma Boundary of Magnetic Fusion Devices (Institute of Physics Publishing, Bristol, 2000), p. 563.

${ }^{26}$ T. Eich, B. Sieglin, A. Scarabosio, W. Fundamenski, R. J. Goldston, A. Herrmann, and ASDEX Upgrade Team, Phys. Rev. Lett. 107, 215001 (2001).

${ }^{27}$ R. J. Goldston, Nucl. Fusion 52, 013009 (2012). 